Journal of Animal and Veterinary Advances 9 (17): 2315-2320, 2010

ISSN: $1680-5593$

(C) Medwell Journals, 2010

\title{
Real-time PCR Assay Based Glyceraldehydes 3-Phosphate Gene for Identification of Brucella sp.
}

\author{
${ }^{1}$ Seong Guk Kim, ${ }^{1}$ Yeong Hwan Kim, ${ }^{2}$ Myeong Ju Chae, \\ ${ }^{3}$ Jong Wan Kim and ${ }^{2}$ Young Ju Lee \\ ${ }^{1}$ Gyeongbuk Veterinary Service Laboratory, Daegu, Republic of Korea \\ ${ }^{2}$ College of Veterinary Medicine, Kyungpook National University, \\ Daegu, Republic of Korea \\ ${ }^{3}$ National Veterinary Research and Quarantine Service, \\ Ministry of Agriculture and Forestry, Anyang, Republic of Korea
}

\begin{abstract}
Brucellosis is one of the most important zoonoses which affects both animals and humans and leads to serious economic and public health problems. The aim of this study was to design, optimize and evaluate real-time PCR assay for Brucella sp. detection by targeting gap gene and to compare to those of conventional PCR assays. A low variation in $\mathrm{C}_{\mathrm{T}}$ values was observed for the gap gene target when the same quantity of DNA for 5 Brucella reference strains was used as template in the assays ( $\mathrm{C}_{\mathrm{T}}$ : $21-23$ with $500 \mathrm{pg}$ of Brucella DNA). No amplification products were observed in real-time PCR whatever the target with any of the 50 non-Brucella organisms tested. In the analytical sensitivity of real-time PCR assay based gap gene of B. abortus biovar 1 RB51, DNA concentration of 5 fg was successfully amplified and the sensitivity of the gap-based TaqMan real-time PCR assay was identical and 10-100 times higher than the sensitivity of the three conventional PCR. In the clinical trial, $9(16.3 \%)$ and $11(21.2 \%)$ among 52 blood samples from cows confirmed with B. abortus infection by Rose Bengal Spot agglutination test were positive in culture of B. abortus and gap real-time PCR, respectively. In conclusion, the use of the gap-based TaqMan real-time PCR assay appears promising due to it high sensitivity for the simple, faster and specific detection of the Brucella sp.
\end{abstract}

Key words: Real-time PCR, Brucella sp., glyceraldehydes 3-phosphate gene, conventional PCR assays, zoonoses

\section{INTRODUCTION}

Brucellosis is one of the most important zoonoses which affects both animals and humans and leads to serious economic and public health problems. The genus Brucella has classically been divided into six species based on host specificity including $B$. abortus, $B$. melitensis, B. suis, B. ovis, B. neotomae and B. canis (Corbel and Brinley-Morgan, 1984). About 2 new species, B. cataceae and B. pinnipediae have been discovered recently in marine mammals (Cloeckaert and Vizcaino, 2002).

Diagnosis of brucellosis in humans and animals is initially made by use of appropriate serological or other immunological tests and confirmed by bacteriological isolation and identification of the agent. Serological assays are rapid, sensitive and easy to perform but lack specificity due to cross-reaction with other bacteria, particularly with Yersinia enterocolitica $0: 9$ that result from O chains antigenic similarity (Godfroid et al., 2002; Nielsen et al., 2004). Moreover, the identification of
Brucella sp. relies on an array of approximately 25 phenotypic traits like biochemical characteristics, serological typing and phage typing and requires long times such as 10-14 days with well-equipped laboratories and highly skilled specialist (Lopez-Goni and Moriyon, 2004).

PCR-based methods are fast, simple, less hazardous and more sensitive (Bricker, 2002). Gene targets for detection and identification of pathogens using PCR have included Brucella sp. outer membrane proteins, 16S rRNA gene sequences, 16S-23S spacer regions, housekeeping genes, erythritol utilization genes and insertion sequences (IS711) (Al Dahouk et al., 2007; Debeaumont et al., 2005; Queipo-Ortuno et al., 2005). Glycealdehyde-3-phosphate dehydrogenase (gap) gene with various degrees of similarity is a kind of housekeeping genes and present Brucella sp. and present in a few other bacteria including Yersinia enterocolitica $0: 9$, Vibrio cholerae $\mathrm{O} 1$ and Escherichia coli O:157 (Figge et al., 1999). Most recently, real-time PCR assays for the detection of Brucella sp. have been developed (Al Dahouk et al., 2007;

Corresponding Author: Young Ju Lee, College of Veterinary Medicine, Kyungpook National University, Daegu, Republic of Korea 
Gopaul et al., 2008; Navarro et al., 2006). Real-time PCR is a variation of the standard PCR technique used to quantify DNA or messenger RNA in a specimen such as milk, blood, tissues and uses to compare relative copy numbers between tissues, organisms or different genes relative to a specific housekeeping gene that are generally always expressed and thought to be involved in routine cellular metabolism. The aim of this study was to design, optimize and evaluate real-time PCR assay for Brucella sp. detection by targeting the gap gene and to compare to those of conventional PCR assays already published.

\section{MATERIALS AND METHODS}

Bacterial strains: The Brucella strains used in this study included the reference strains of $B$. abortus biovar 12308 , B. abortus biovar 1 RB51, B. melitensis biovar 3 ether, $B$. suis biovar 1 1330, B. ovis 63/290 and B. canis RM6/66 received from National Veterinary Research and Quarantine Service in Korea and the field isolates of B. abortus $\mathrm{GB} 1$, B. abortus $\mathrm{GB} 2$, B. abortus GB3, B. canis GB1 and B. canis GB2. Non-Brucella sp. tested were 4 Shigella sonnei, 15 Escherichia coli, 15 Salmonella sp. 4 Staphylocaccus aureus, 1 Bacillus anthrax, 4 Yersinia enterocolitica, 4 Bacillus cereus, 1 Vibrio cholera and 2 Listeria monocytogenes.

DNA extraction and quantification: Genomic DAN of all micro-organisms was extracted using QIAamp DNA Mini kit (Qiagen, France) according to manufacturer's directions. The DNA concentration was measured spectrophotometrically at A260 and a volume of $2 \mu \mathrm{L}$ of aliquot was used as the template DNA in the conventional and real-time PCR.

Primers and probes: The primers using as targets the Brucella cell surface $31 \mathrm{kDa}$ protein (bcsp31), 16s rRNA and IS711 for conventional PCR have been previously described (Baily et al., 1992; Mackay et al., 2002; Romero et al., 1995). By contrast, primers used for realtime PCR based gap gene were newly designed on the basis of gap sequences available in the GenBank by using multiple sequence alignment (Fig. 1). The gap probe was a TaqMan probe (Applied Biosystems, France) incorporating a 5' FAM reporter and a minor groove binder group with a non-fluorescent quencher at the 3 ' end.

Conventional PCR assay: Amplification was performed in $50 \mu \mathrm{L}$ volume with a PCR buffer containing $10 \mathrm{mM}$ Tri-HCl (pH 8.3), $50 \mathrm{mM} \mathrm{KCl}, 1.5 \mathrm{mM} \mathrm{MgCl}_{2}, 250 \mathrm{mM}$ concentration of each deoxynucleoside triphosphate (Promega,USA), 5 U of Taq polymerase (Qiagen, France), a 50 pmol concentration of each primer and $4 \mu \mathrm{L}$ of DNA. The DNA quantities used for the analytical sensitivity corresponded to 10 fold dilution from $5 \mu \mathrm{g}\left(1.5 \times 10^{7}\right.$ genome equivalents $)$ to $5 \mathrm{fg}(1.5 \times 10$ genome equivalents $)$.

Real-time TaqMan PCR: Real-time PCR was set up in a final volume of $25 \mu \mathrm{L}$ with $7 \mu \mathrm{L}$ of RNase free water, $8 \mu \mathrm{L}$ of PowerChek ${ }^{\mathrm{TM}}$ Brucella sp. real-time PCR Kit (KOGEN Biotech Co., Korea) each primer and TaqMan probe at concentration of 10 and $1 \mathrm{pmol}$, respectively and $2 \mu \mathrm{L}$ of DNA template. The reaction mixture was incubated for $5 \mathrm{~min}$ at $95^{\circ} \mathrm{C}$. Amplication was performed for 40 cycles of denaturation at $95^{\circ} \mathrm{C}$ for $15 \mathrm{sec}$, annealing at $58^{\circ} \mathrm{C}$ for $30 \mathrm{sec}$ and extension at $72^{\circ} \mathrm{C}$ for $30 \mathrm{sec}$. The PCR reaction was performed on an ABI 7500 Real-time PCR systems (ABI, USA). Detection limit was assessed using pGEM $^{\circledR}$ T-Easy Vector (Promega Co. Madison, USA)-based plasmid, containing the target sequences of $B$. abortus RB51 that were cloned according to the manufacturer's protocol and determined three times by analyzing a dilution series of the prepared plasmid DNA in PCR-grade water ranging from 500-5 fg. Negative controls were also included and contained all the elements of the reaction mixture except template DNA.

Clinical samples: About 52 blood samples from cows in this study confirmed with $B$. abortus antibody positive by Rose Bengal Spot agglutination Test (RBT) were tested in this study. All cows were in the farms where brucellosis

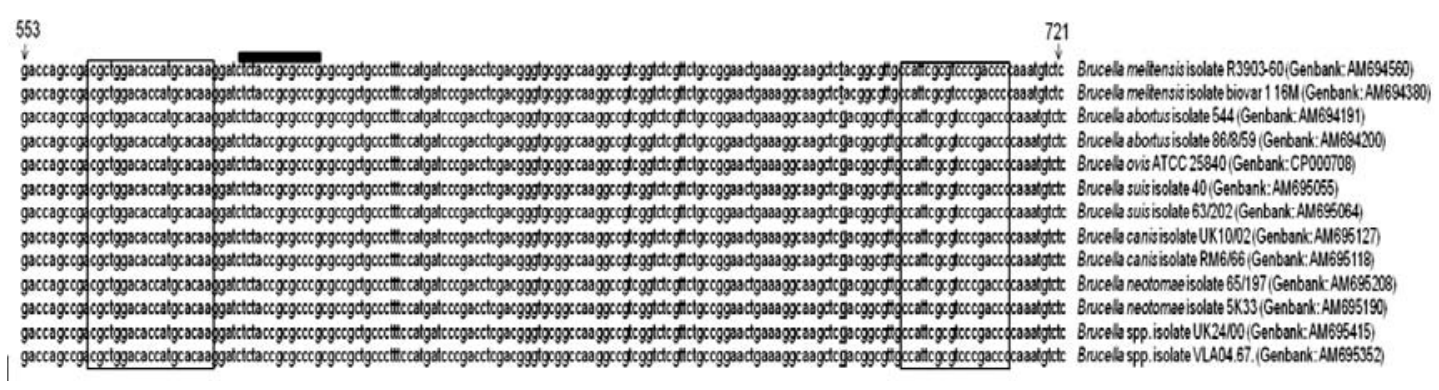

Fig. 1: Aligments of various gap gene sequences around of the gap ${ }_{586 / 600}$ probes. The alignment contains 13 sequences taken directly from Genbank. In this figure, the variable region of Brucella sp. are bold and underlined and the black bar above figures represents the location of probe hybridization 
was occurred before. For cultivation of blood samples, $1 \mathrm{~mL}$ of whole blood mixed with $4 \mathrm{~mL}$ of leukocyte lysis solution $(0.32 \mathrm{M}$ sucrose, $10 \mathrm{mM}$ tris base, $1 \%$ triton $\mathrm{X}-100,5$ mM magnesium chloride in distilled water, $\mathrm{pH} 7.5$ ) and incubated for $5 \mathrm{~min}$ at room temperature. The mixture was centrifuged at $3,000 \mathrm{rpm}$ for $30 \mathrm{~min}$ and the supernatant was removed. The cell sediment was spread evenly on $5 \%$ sheep blood agar medium and the plates were incubated at $37^{\circ} \mathrm{C}$ for $48-72 \mathrm{~h}$ (Gaviria-Ruiz and Cardona-Castro, 1995). Suspicious colonies sized 1-2 mm in diameter, appearing nonhemolytic and light gray were confirmed by conventional PCR method tested in this study. DNA from blood sample was extracted from $200 \mu \mathrm{L}$ of EDTA anticoagulated whole blood and used QIAamp DNA Mini kit (Qiagen, France) according to manufacturer's direction. Sera were tested for antibodies against Brucella sp. using competitive ELISA (SVANOVIR ${ }^{\circledR}$ Brucella-Ab c-ELISA, Svanova Biotech AG Uppsala, Sweden) and RBT as recommended by the OIE Manual of Standards for Diagnostic Tests and Vaccines, 2008 (Office International des Epizooties OIE, 2008). The cut-off value for the c-ELISA was determined according to the manufacturer's guidelines.

\section{RESULTS AND DISCUSSION}

A low variation in $\mathrm{C}_{\mathrm{T}}$ values was observed for gap gene target when the same quantity of DNA for reference strains of B. abortus, B. melitensis, B. suis, B. ovis and $B$. canis was used as a template in the assays $\left(\mathrm{C}_{\mathrm{T}}\right.$ : 21-23 with $500 \mathrm{pg}$ of Brucella DNA) (Fig. 2). No amplification products were observed in real-time PCR whatever the target with any of the 50 non-Brucella organisms tested. The analytical sensitivity of real-time PCR assay based gap gene of $B$. abortus biovar 1 RB51 was tested at least three times for each serial dilution from 500-5 fg (Fig. 3). In fact, DNA concentration of $5 \mathrm{fg}$ was successfully amplified. In every instance, the amplification was clearly distinguishable from the no-template controls. The respective lower limit of detections of conventional and real-time PCR assay observed with 10 fold dilutions of B. abortus, B. melitensis, B. suis, B. ovis and B. canis DNA are shown in Table 1. In all cases, the real-time PCR was more sensitive than conventional PCR assay. In conventional PCR assays, the lower limit of detection was identical to IS711 target. But the sensitivity of the gap-based TaqMan real-time PCR assay was identical and 10-100 times higher than the sensitivity of the three conventional PCR assays.

The result of $B$. canis isolation and gap real-time PCR from 52 blood samples with $B$. abortus seropositve are shown in Table 2 . Only $9(16.3 \%)$ and $11(21.2 \%)$ samples were positive in isolation of $B$. abortus and gap real-time $\mathrm{PCR}$, respectively. Otherwise, $49(94.2 \%)$ samples were positive in c-ELISA.

The aim of this study was to develop a rapid and sensitive detection method for multiple Brucella serotypes based on real time RCR and to compare it to traditional PCR methods. Real-time PCR methods have proven themselves valuable in general laboratories as a rapid diagnostic method and substitute to traditional PCR assays. The basis of rapid specific region detection of real-time PCR assay is principally due to reduced cycle times and omitted post-PCR detection procedures as electrophoresis of agarose gel in the ethidium bromide for analysis of the resulting specific band after irradiation by ultraviolet light (Mackay et al., 2002).

For the development of the real-time PCR assay, primers were designed specifically for Brucella. To the knowledge, no previously published real-time PCR presented primers based gap gene while this sequence is specific and its specificity was confirmed with at least 50
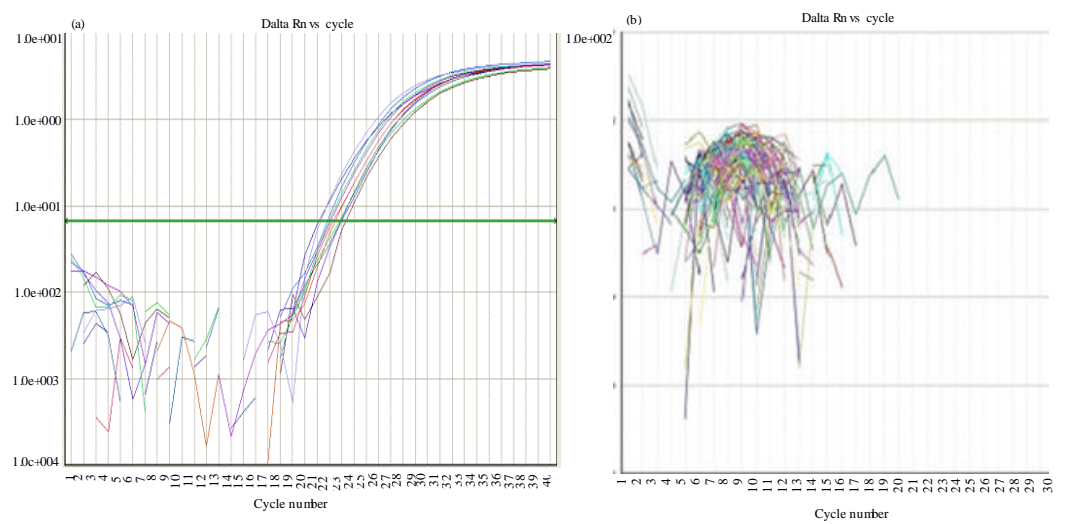

Fig. 2: Real-time PCR amplification curves of $B$ abortus, B melitensis, B suis, $B$ ovis and $B$ canis reference strains (a) and 50 non-Brucella sp. genomic DNA (b) tested in this study. The concentration of genomic DNA was adjusted to $5 \mathrm{ng}$ 


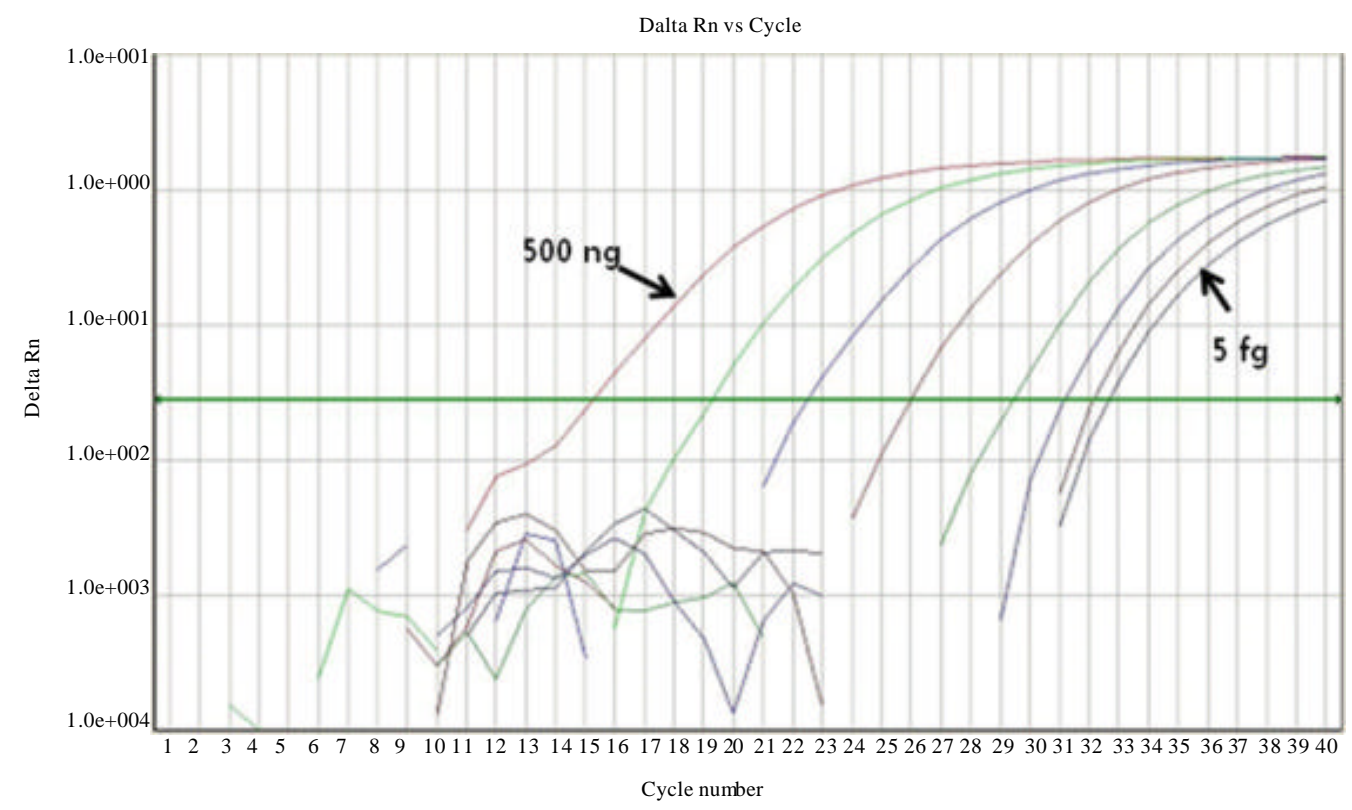

Fig. 3: Real-time PCR amplification curves of B. abortus biovar 1 RB51 genomic DNA. A 10 fold dilution series from $500 \mathrm{ng}-5 \mathrm{fg}$ was used as a template

Table 1: Comparison of convention and real-time PCR assays lower limit of detection ( $\mathrm{fg}$ )

\begin{tabular}{|c|c|c|c|c|c|}
\hline \multirow[b]{2}{*}{ Organisms } & \multirow[b]{2}{*}{ References } & \multicolumn{3}{|c|}{ Conventional PCR } & \multirow[b]{2}{*}{ Real-time PCR } \\
\hline & & Bcsp31 & 16S-rRNA & IS711 & \\
\hline B. abortus biovar $12308^{a}$ & - & 500 & 500 & 50 & 5 \\
\hline B. abortus biovar $1 \mathrm{RB} 51^{\mathrm{a}}$ & - & 500 & 500 & 50 & 5 \\
\hline B. melitensis biovar 3 ether $^{\mathrm{a}}$ & ATCC 23458 & 500 & 500 & 500 & 50 \\
\hline B. suis biovar $11330^{\mathrm{a}}$ & ATCC 23444 & 500 & 500 & 50 & 5 \\
\hline B. ovis $63 / 290^{\mathrm{a}}$ & ATCC 25840 & 500 & 500 & 50 & 5 \\
\hline B. canis $\mathrm{RM} 6 / 66^{\mathrm{a}}$ & ATCC 23365 & 500 & 500 & 50 & 50 \\
\hline B. abortus $\mathrm{GB1}^{\mathrm{b}}$ & Field strain & 500 & 500 & 50 & 5 \\
\hline B. abortus $\mathrm{GB} 2^{b}$ & Field strain & 500 & 500 & 50 & 5 \\
\hline B. abortus $\mathrm{GB}^{b}$ & Field strain & 500 & 500 & 50 & 5 \\
\hline B. canis $\mathrm{GB} 1^{\mathrm{b}}$ & Field strain & 500 & 500 & $\mathrm{NT}^{\mathrm{a}}$ & 50 \\
\hline B. canis $\mathrm{GB}^{b}$ & Field strain & 500 & 500 & NT & 50 \\
\hline Non-Brucella sp. ${ }^{\mathrm{b}, \mathrm{c}}$ & - & & & & \\
\hline
\end{tabular}

${ }^{a}$ Strains were obtained from National Veterinary Research and Quarantine Service (Korea). ${ }^{b}$ Strains were kept in Kyungsangbuk-do Veterinary Service Laboratory (Korea). ${ }^{~}$ Non-Brucella sp. tested in this study were 4 Shigella sonnei, 15 Escherichia coli, 15 Salmonella sp. 4 Staphylocaccus aureus, 1 Bacillus anthrax, 4 Yersinia enterocolitica, 4 Bacillus cereus, 1 Vibrio cholera and 2 Listeria monocytogenes

Table 2: Comparison of isolation of $B$. abortus and real-time PCR from 52 blood samples in cows confirmed with $B$. abortus antibody positive by Rose Bengal Spot agglutination test

\begin{tabular}{lcc}
\multicolumn{3}{c}{ positive by Rose Bengal Spot agglutination test } \\
\hline & Positive samples detected \\
\cline { 2 - 3 } Methods & Number & Percentage \\
\hline c-ELISA & 49 & 94.2 \\
Culture & 9 & 16.3 \\
gap real-time PCR & 11 & 21.2 \\
\hline
\end{tabular}

non-Brucella organisms of closely related or clinically relevant bacteria. A greater sensitivity was observed for the gap gene detection by real-time PCR and could reliably detect DNA down to $5 \mathrm{fg}$. The one set of real-time PCR gap primer presented in this study was selected among many pairs after intensive testing. This careful design of the gap primers allowed for a significant improvement of the specificity of the assay since no cross-reaction was observed. Gopaul et al. (2008) described a detection limit of $50 \mathrm{fg}$ for B. melitensis with real-time PCR based single nucleotide polymorphism analysis. In IS711 real-time PCR assay described by Newby et al. (2003) was able to detect $7.5 \mathrm{fg}$ of B. abortus DNA. Bogdanovich et al. (2004) described a detection limit of 2,000 fg for B. abortus, B. melitensis and B. suis DNA and $200 \mathrm{fg}$ for B. neotomae and B. ovis DNA with a per gene-based real-time PCR.

Bounaadja et al. (2009) reported that the specificity of conventional PCR assays presented similar results to in this study and 10 fold maximum variation was observed 
according to the species tested with a 50-500 higher sensitivity for the real-time PCR. In this study, the sensitivity of the conventional PCR with IS711 target was also identical or 10 times higher than two other targets because of copy numbers among Brucella species and biovars but presented lower sensitivity than real-time PCR based gap gene.

But, the results of the study suggest that whole blood is not a good template for the detection of $B$. abortus DNA. Culture is considered the gold standard in the laboratory diagnosis of brucellosis in human, although many cases can be missed by culture. Yagupsky (1999) reported the sensitivity of blood culture has ranged from $40-90 \%$. Blood is also the first sample for diagnosis of bovine brucellosis without slaughter of suspicious cows.

But bacterial detection by blood samples may be influenced by the number of circulating bacteria, the host's immune response, the intracellular character, etc (Born et al., 1976; Herlich et al., 1982). Leal-Klevezas et al. (1995) reported that the PCR performance with the Brucella DNA extracted from blood samples is very often compromised by the presence of PCR inhibitors and further complicated because Brucella is an intracellular pathogen. O'Leary et al. (2006) also reported that the presence of large amount of bovine genomic DNA may have inhibitory affects on the PCR assay. Therefore, the real-time PCR assay based gap gene should be more carefully validated again on clinical samples.

\section{CONCLUSION}

In conclusion, the use of the gap-based TaqMan real-time PCR assay appears promising due to its high sensitivity for the simple, faster and specific detection of Brucella and the optimal clinical specimen for real-time PCR diagnosis of bovine brucellosis remains to be determined.

\section{REFERENCES}

Al Dahouk, S., K. Nockler, H. C. Scholz, M. Pfeffer, H. Neubauer and H. Tomaso, 2007. Evaluation of genus-specific and species-specific real-time PCR assays for the identification of Brucella sp. Clin. Chem. Lab. Med., 45: 1464-1470.

Baily, G.G., J. B. Krahn, B.S. Drasar and N.G. Stoker, 1992. Detection of Brucella melitensis and Brucella abortus by DNA amplification. J. Trop. Med. Hyg., 95: 271-275.

Bogdanovich, T., M. Skurnik, P.S. Lubeck, P. Ahrens and J. Hoorfar, 2004. Validated 5 nuclease PCR assay for rapid identification of the genus Brucella. J. Clin. Microbiol., 42: 2261-2263.
Born, G.L., J.R. Haynes and G.G. Burson, 1976. Blood culture technique based on centrifugation: Developmental phase. J. Clin. Microbiol., 3: 251-257.

Bounaadja, L., D. Albert, B. Chenais, S. Henault, M.S. Zygmunt, S. Poliak and B. Garin-Bastuji, 2009. Real-time PCR for identification of Brucella spp.: A comparative study of IS711, bcsp31 and per target genes. Vet. Microbiol., 137: 156-164.

Bricker, B.J, 2002. PCR as a diagnostic tool for brucellosis. Vet. Microbiol., 90: 435-446.

Cloeckaert, A. and N. Vizcaino, 2002. DNA polymorphism and taxonomy of Brucella species. In: Brucella: Molecular and Cellular Biology, Lopez-Goni I. and I. Moriyon (Eds.), Horizon Bioscience, Norfolk, United Kingdom, pp: 1-24.

Corbel, M.J. and W.J. Brinley-Morgan, 1984. Genus Brucella Meyer and Shaw 1920, 173AL. Williams and Wilkins, Baltimore, MD.

Debeaumont, C., P.A. Falconnet and M. Maurin, 2005. Real-time PCR for detection of Brucella spp. DNA in human serum samples. Eur. J. Clin. Microbiol. Infect. Dis., 24: 842-845.

Figge, R.M., M. Schubert, H. Brinkmann and R. Cerff, 1999. Glyceraldehyde-3-phosphate dehydrogenase gene diversity in eubacteria and eukaryotes: Evidence for intra- and inter-kindom gene transfer. Mol. Boil. Evol., 16: 429-440.

Gaviria-Ruiz, M.M. and N.M. Cardona-Castro, 1995. Evaluation and comparison of different blood culture techniques for bacteriological isolation of Salmonella typhi and Brucella abortus. J. Clin. Microbiol., 33: 868-871.

Godfroid, J., C. Saegerman, V. Wellemans, K. Walravens and J.J. Letesson et al., 2002. How to substantiate eradication of bovine brucellosis when aspecific serological reactions occur in the course of brucellosis testing. Vet. Microbiol., 90: 461-477.

Gopaul, K.K., M.S. Koylass, C.J. Smith and A.M. Whatmore, 2008. Rapid identification of Brucella isolates to the species level by real time PCR based single nucleotide polymorphism (SNP) analysis. BMC Microbiol., 8: 86-99.

Herlich, M.B., R.F. Schell, M. Francisco and J.L. Le Frock, 1982. Rapid detection of simulated bacteremia by centrifugation and filtration. J. Clin. Microbiol., 16: 99-102.

Leal-Klevezas, D.S., I.O. Martinez-Vazquez, A. LopezMerino and J.P. Martinez-Soriano, 1995. Single-step PCR for detection of Brucella spp. from blood and milk of infected animals J. Clin. Microbiol., 33: 3087-3090.

Lopez-Goni, I. and I. Moriyon, 2004. Brucella: Molecular and Cellular Biology. Horizon Bioscience, Norfolk, England, pp:1-428. 
Mackay, I.M., K.E. Arden and A. Nitsche, 2002. Real-time PCR in virology. Nucleic Acids Res., 30: 1290-1305.

Navarro, E., J.C. Segura, M.J. Castano and J. Solera, 2006. Use of real-time quantitative polymerase chain reaction to monitor the evolution of Brucella melitensis DNA load during therapy and posttherapy follow-up in patients with brucellosis. Clin. Infect. Dis., 42: 1266-1273.

Newby, D.T., T.L. Hadfield and F.F. Roberto, 2003. Realtime PCR detection of Brucella abortus: A comparative study of SYBR green I, 59-exonuclease, and hybridization probe assays. Appl. Environ. Microbiol., 59: 4753-4759.

Nielsen, K., P. Smith, J. Widdison, D. Gall, L. Kelly, W. Kelly and P. Nicoletti, 2004. Serological relationship between cattle exposed to rucella abortus, Yersinia enterocolitica O:9 and Escherichia coli O157:H7. Vet. Microbiol., 100: 25-30.
O'Leary, S., M. Sheahan and T. Sweeney, 2006. Brucella abortus detection by PCR assay in blood, milk and lymph tissue of serologically positive cows. Res. Vet. Sci., 81: 170-176.

Office International des Epizooties OIE., 2008. Manual of standards for Diagnostic Tests and Vaccines. Office International des Epizooties O.I.E., Paris.

Queipo-Ortuno, M.I., J.D. Colmenero, J.M. Reguera, M.A. García-Ordonez, M.E. Pachon, M. Gonzalez and P. Morata, 2005. Rapid diagnosis of human brucellosis by SYBR Green I-based real-time PCR assay and melting curve analysis in serum samples. Clin. Microbiol. Infect., 11: 713-718.

Romero, C., C. Gamazo, M. Pardo and I. Lopez-Goni, 1995. Specific detection of Brucella DNA by PCR. J. Clin. Microbiol., 33: 615-617.

Yagupsky, P., 1999. Detection of brucellae in blood cultures. J. Clin. Microbiol., 37: 3437-3442. 